\title{
Pengaturan Laju Aliran FluidaUntuk Meningkatkan Laju Perpindahan Panas Pada Solar Water Heater Di Kota Pontianak
}

\author{
Rusadi \\ Program Studi Manajemen Energi, Magister Teknik Elektro \\ Fakultas Teknik, Universitas Tanjungpura Pontianak, \\ Jurusan Teknik Mesin Politeknik Negeri Pontianak \\ email : rus4di@gmail.com
}

\begin{abstract}
Issues about the energy crisis and clean energy in the environment become an important issue. Energy that meets the above properties is solar energy. Utilization is highly dependent on climate and weather conditions in accordance with the geographical location of the place. Optimization of energy absorption needs to be done and this is usually done by conditioning or manipulating some parameters so that the level of energy absorption is more effective and efficient.

This research is an expriment research by optimizing the absorption of heat energy to heat water according to climate and weather conditions in Pontianak, West Kalimantan. The variable to be conditioned or arranged so that the maximum heat transfer rate is the flow rate of the water fluid to be heated.

The experimental results show that the water flow rate of $2450 \mathrm{ccm}$ DHW Loop side for SHW has a temperature difference value on the exit side of the heat exchanger which is smaller than the others. This shows that the more effective the release and absorption of heat made by the fluid in the heat exchanger.

Keywords-Solar energy, Solar Water Heater (SHW), fluid flow rate, heat transfer rate
\end{abstract}

\section{Pendahuluan}

Untuk meningkatkan temperatur air, tentu butuh energi panas. Mengingat krisis energi melanda dunia maka perlu dilakukan penghematan penggunaan cadangan energi yang ada. Selain krisis energi yang dialami, isu tentang Green Energy yaitu tentang energi bersih dan ramah lingkungan juga menjadi suatu isu yang sangat penting saat ini. Energi yang mempunyai sifat di atas adalah energi baru terbarukan yang salah satunya adalah Energi Matahari.

Salah satu bentuk pemanfaatan energi matahari saat ini adalah pemanfaatan energi matahari dengan menyerap energi menggunakan Solar Collector. Biasanya digunakan untuk pemanas air dan biaya pengoperasiannya rendah. Prinsip kerjanya dengan melewatkan air pada solar collector sehingga terjadi perpindahan panas dari solar collector ke air. Besarnya energi yang bisa dimanfaatkan juga tergantung kepada intensitas dari energi matahari yang dipancarkan sehinggasangat bergantung sekali pada iklim dan kondisi cuaca.

Dalam tulisan ini, penulis membahas pemanfaatan energi panas matahari menjadi sumber energi yang akan digunakan untuk memanaskan air. Pemanfaatan ini sangat tergantung kepada iklim dan kondisi cuaca sesuai dengan letak geografis tempat tersebut. Penelitian ini dilakukan dengan iklim dan kondisi cuaca di wilayah Kota Pontianak Kalimantan Barat.

Pengoptimalan penyerapan energi perlu dilakukan dan ini dilakukan dengan mengkondisikan atau memanipulasi beberapa parameter sehingga tingkat penyerapan energinya semakin efektif dan efisien.

Pengaruh laju aliran fluida dingin yang mengalirpada Shell and Tube Heat Exchanger dapat menyebabkan perubahan laju perpindahan panas. Ini disebabkan oleh meningkatnya laju aliran akan menyebabkan Reynold Number meningkat yang diikutidenganmeningkatnya Stanton Number dankoofisienperpindahanpanaslapisan film (film cooficient heat transfer) [1]. Dalam penelitian ini parameter yang dikondisikan dan diatur adalah laju aliran dari air yang akan dipanaskan.

Dengan jumlah laju aliran fluida yang optimal diharapkan laju perpindahan panas juga berlangsung dengan efektif dan efisien. Solar Water Heater yang digunakan dalam eksprimen ini bisa diatur sudut datang sinar matahari dan laju aliran fluidanya.

\section{TeoriDasar}

\subsection{Solar Water Heater}

Solar Water Heater adalah sebuah sistem dimana panas matahari dikumpulkan oleh kolektor surya dan digunakan untuk meningkatkan suhu cairan pentransfer panas (air atau cairan anti beku) yang mengalir melalui pipa-pipa di kolektor; panas yang terkandung dalam cairan ini kemudian disampaikan dan dipindahkan ke air domestik.

\subsection{Perpindahan Panas Dan Mekanisme}

Perpindahan panas dapat didefinisikan sebagai perpindahan energy sebagai akibat dari perbedaan temperatur yang arah perpindahannya dari temperature tinggi ke temperature lebih rendah.

Ada tiga proses perpindahanpanas yaitu:

1. Konduksi

Proses perpindahan kalor konduksi adalah proses perpindahan kalor yang melibatkan aktifitas dari atom atau molekul. Konduksi dapat dipandang sebagai suatu bentuk transfer energi dari energi tinggi ke energi rendah sebagai akibat interaksi antar partikel. 
Sumber: [2:4]

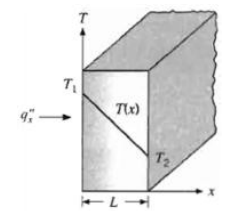

Gambar 1. Perpindahan kalor konduksi satu dimensi Untuk bidang satu dimensi dengan distribusi temperatur $\mathrm{T}(\mathrm{x})$ seperti yang ditunjukan pada gambar 1 maka persamaannya adalah $[2 ; 4]$ :

$$
\mathrm{q}_{\mathrm{x}}^{\prime \prime}=-\mathrm{k} \frac{\mathrm{dT}}{\mathrm{dx}}
$$

Laju fluks kalor $q^{\prime \prime}\left(W / m^{2}\right)$ adalah laju perpindahan panas dalam arah $x$ per satuan luas tegak lurus arah perpindahan dan sebanding dengan gradien temperatur $\frac{d T}{d x}$ dalam arah yang sama. Parameter $\mathrm{k}$ adalah konduktifitas panas $(\mathrm{W} / \mathrm{m} . \mathrm{K})$ yang merupakan karakteristik dari material. Sedangkan tanda minus menunjukkan konsekuensi bahwa arah perpindahan panas adalah ke temperatur yang rendah.

\section{Konveksi}

Konveksi merupakan jenis perpindahan kalor yang terjadi karena 2 jenis mekanisme. Yang pertama adalah perpindahan energi akibat gerakan random dari molekul atau biasa juga disebut dengan diffusion dan yang kedua adalah perpindahan energi disebabkan oleh pergerakan makrokospik dari fluida atau biasa dikenal dengan bulk.

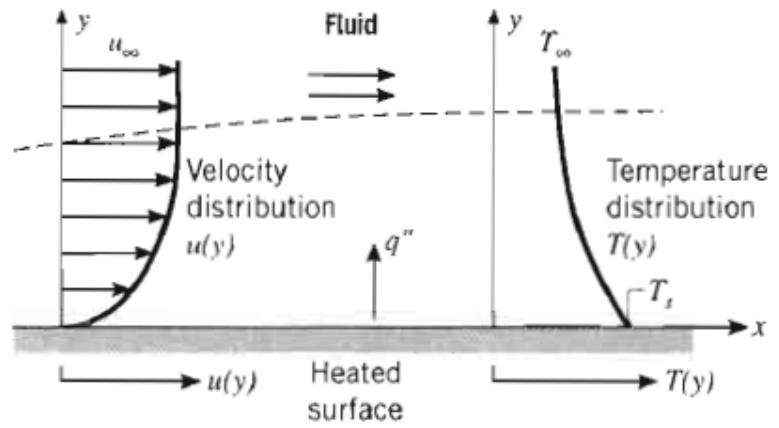

Sumber: $[2 ; 6]$

Gambar 2. Lapisan boundary pada perpindahan kalor konveksi

Gambar 2 menggambarkan sebuah fluida yang bergerak di atas permukaan yang dipanaskan. Distribusi kecepatan arah $y(u(y))$ akan mendekati atau dianggap 0 jika berada pada permukaan dan akan makin cepat jika menjauhi permukaan. Sedangkan distribusi temperatur dalam arah $y(T(y))$ akan makin rendah jika jauh dari permukaan. Ilustrasi ini dibuat untuk menggambarkan mekanisme perpindahan kalor konveksi yang terjadi antara fluida bergerak dan sebuah permukaan dimana terdapat perbedaan temperatur.

Untuk perpindahan kalor konveksi (bebas/alami) laju perpindahan panasnya per satuan luas dapat dicari dengan menggunakan persamaan[2;8]:

$$
\mathrm{q}^{\prime \prime}=\mathrm{h}\left(\mathrm{T}_{\mathrm{s}}-\mathrm{T}_{\infty}\right)
$$

Jika persamaan di atas adalah fluks kalor konveksi diasumsikan positif jika panas dipindahkan dari permukaan $\left(\mathrm{T}_{\mathrm{S}}>\mathrm{T}_{\infty}\right)$ dan negatif jika panas berpindah ke permukaan $\left(\mathrm{T}_{\infty}>\mathrm{T}_{\mathrm{S}}\right)$. Apabila panas berpindah ke permukaan maka hukum Newton tentang pendinginan ( Newton's Law of Cooling) menjadi [2;9] :

$$
\mathrm{q}^{\prime \prime}=\mathrm{h}\left(\mathrm{T}_{\infty}-\mathrm{T}_{\mathrm{s}}\right)
$$

3. Radiasi

Radiasi thermal adalah proses pemancaran energy oleh material pada temperatur di atasnol (0). Energi yang berasal dari radiasi dipindahkan oleh gelombang elektro magnetik sehingga untuk radiasi tidak memerlukan media untuk perpindahan tidak seperti pada konduksi maupun konveksi. Dan pada kenyataannya, perpindahan energy pada radiasi jauh lebihe fektif pada kondisi vakum.

Radiasi dipancarkan oleh permukaan yang berasal dari energy sebuah material yang dibatasi oleh permukaan dan laju energi yang dilepas per unit area disebut dengan daya emisitas permukaan (surface emissive power), disimbol kandengan $\mathrm{E}\left(\mathrm{W} / \mathrm{m}^{2}\right)$. Besar daya emisitas dapat dicari dengan menggunakan StefanBolt zmann Law yaitu [2;9]:

$$
\mathrm{E}_{\mathrm{b}}=\sigma . \mathrm{T}_{\mathrm{s}}^{4}
$$

Dengan $\mathrm{T}_{\mathrm{s}}$ adalah temperatur absolut $(\mathrm{K})$ dari permukaan dan $\sigma$ konstanta Stefan Boltzmann yang besarnya adalah $5,67 \times 10^{-8} \mathrm{~W} / \mathrm{m}^{2} . \mathrm{K}$. Permukaan dianggap sebagai radiator ideal atau blackbody.

Flukskalor yang di emisikan oleh permukaan sebenarnya lebih kecil dibandingkan dengan permukaan hitam sempurna (blackbody) pada temperatur yang sama dan dinyatakan dengan persamaan $[2 ; 9]$ :

$$
\mathrm{E}_{\mathrm{b}}=\in . \sigma . \mathrm{T}_{\mathrm{s}}^{4}
$$

Konstanta $\in$ disebut juga dengan Emisivitas yang menunjukan sifatpancarandari permukaan. Nilainya berada pada range $0 \leq \in \leq$, nilai ini menunjukan tingkat efisiensi dari permukaan untuk memancarkan energi relatif terhadap blackbody.

Pada kasus khusus yang sering terjadi, melibatkan pertukaran radiasi diantara sebuah permukaan kecil pada $\mathrm{T}_{\mathrm{s}}$ dan permukaan yang lebih besar berupa permukaan isothermal yang mengelilingi permukaan kecil. Sekelilingnya sebagai contoh bisa berupa dinding dari ruangan dapur atau tungku dimana temperatur $T_{\text {sur }}$ berbeda dari permukaan yang dikelilinginya $\left(\mathrm{T}_{\text {sur }} \neq \mathrm{T}_{\mathrm{s}}\right)$. Pada bagian selanjutnya nanti, untuk beberapa kondisi, iradiasi bisa didekati sebagai emisi dari benda hitam sempurna (blackbody) pada $T_{s}$, dalam hal ini $\mathrm{G}=$ $\sigma . \mathrm{T}_{\text {sur }}^{4}$. Jika permukaan diasumsikan menjadi satu untuk $\alpha=\varepsilon$ (pada permukaan abu-abu), laju dari perpindahan kalor radiasi dari permukaan per satuan unit dari permukaan menjadi $[2 ; 10]$ :

$$
\mathrm{q}_{\mathrm{rad}}^{\prime \prime}=\frac{\mathrm{q}}{\mathrm{A}}=\varepsilon \cdot \mathrm{E}_{\mathrm{b}}\left(\mathrm{T}_{\mathrm{s}}\right)-\alpha \cdot \mathrm{G}=\varepsilon \cdot \sigma\left(\mathrm{T}_{\mathrm{s}}^{4}-\mathrm{T}_{\mathrm{sur}}^{4}\right)
$$

\subsection{Heat Exchanger}

Perpindahan panas biasanya digunakan pada alat yang disebut dengan penukar kalor/heat exchanger. Penukar kalor biasanya didesain untuk 2 jenis fluida yang mempunyai temperature yang berbeda yang dipisahkan oleh media konduksi tertentu. 
2.3.1 Desain Aliran Searah dan Berlawanan Penukar Kalor

Walaupun biasanya penukar kalor berbeda secara design, konstruksi dan tipenya ,tetapi prinsip kerja dan efektifitas dari penukar kalor tetap tergantung kepada arah aliran fluida selama terjadi pertukaran panas.

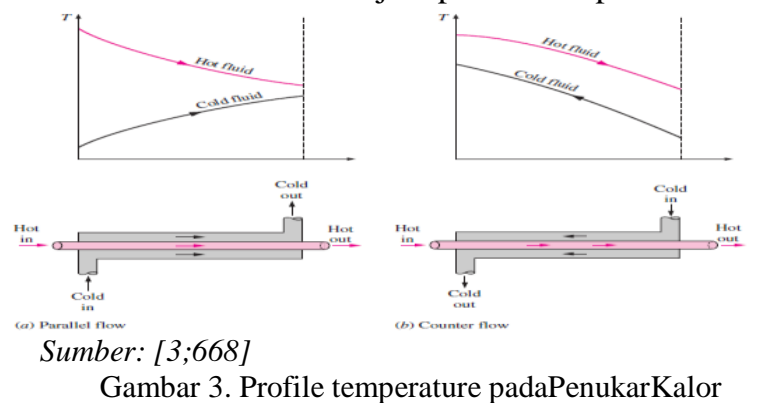

Baik penukar kalor aliran searah maupun berlawanan, perpindahan panas pada penukar kalor pasti melibatkan 2 metode perpindahan panas yaitu konveksi dan konduksi.

\subsection{Aplikasi Log Mean Temperature Difference Pada Penukar Kalor}

Analisis masalah pada heat exchanger dilakukan dengan memperhitungkan keseimbangan energi secara keseluruhan dari masuknya fluida sampai keluarnya fluida. Jumlah keseluruhan panas yang diserap oleh fluida dapat dicari dengan persamaan $[3 ; 680]$ :

$$
\mathrm{q}=\dot{\mathrm{m}} \cdot \mathrm{c}_{\mathrm{p}} \cdot \Delta \mathrm{T}
$$

dimanam, cp, $\Delta \mathrm{T}$ masing-masing adalah lajua liran massa, panas specific dan perubahan temperature dari fluida penyerap panas.

Laju aliran panas yang yang terjadi pada heat exchanger dapat dicari dengan persamaan $[3 ; 681]$ :

$$
\mathrm{q}=\mathrm{U} \cdot \mathrm{A} \cdot \Delta \mathrm{T}_{\mathrm{lm}}
$$

Untuk memecahkan beberapa permasalahan pada penukar kalor, log mean temperature difference (LMTD atau $\Delta \mathrm{T}_{\mathrm{lm}}$ ) harus dicari dulu untuk menghitung perpindahan panas pada penukar kalor. Untuk mencari LMTD atau $\Delta \mathrm{T}_{\mathrm{lm}}$ dapat dicari dengan persamaan [3;681]:

$$
\Delta \mathrm{T}_{\mathrm{lm}}=\frac{\Delta \mathrm{T}_{\text {in }}-\Delta \mathrm{T}_{\text {out }}}{\ln \left\langle\left\langle^{\left.\Delta \mathrm{T}_{1} / \Delta \mathrm{T}_{2}\right\rangle}\right.\right.}
$$

Dengan $\Delta \mathrm{T}_{\text {in }}$ dan $\Delta \mathrm{T}_{\text {out }}$ adalah selisih temperatur pada sisi masuk dan keluar heat exchanger.

2.6 Koofisien Perpindahan Panas Menyeluruh (Overall Cooficient Heat Transfer)

Bila berhubungan dengan perpindahan panas pada tube penukar kalor, maka koofisien perpindahan panas menyeluruh (U) harus dihitung. Nilai koofisien perpindahan panas menyeluruh dapat dihitung dengan persamaan [3;672]:

$$
\mathrm{U}=\frac{1}{\frac{1}{\mathrm{~h}_{\mathrm{i}}}+\frac{\ln \left(\mathrm{D}_{0} / \mathrm{D}_{\mathrm{i}}\right)}{2 \pi \mathrm{kL}}+\frac{1}{\mathrm{~h}_{\mathrm{o}}}}
$$

Apabila dinding dari pipa heat exchanger tipis dan nilai konduktifitas panas (k) dari bahan pipa tinggi maka nilai dari $\frac{\ln \left(\mathrm{D}_{0} / \mathrm{D}_{\mathrm{i}}\right)}{2 \pi \mathrm{kL}}$ dapat diabaikan sehingga persamaan koofisien perpindahan panas menyeluruh menjadi [3;672]:

$$
U=\frac{1}{\frac{1}{h_{i}+\frac{1}{h_{o}}}}
$$

\subsection{Panas Spesifik $\left(c_{p}\right)$}

Panas spesifik yang dicari disini adalah panas spesifik dari Ethyline Gylcol konsentrasi 20\% yang digunakan dalam penelitian ini. Panas spesifik ini dicari untuk mencari jumlah panas yang diangkut oleh fluida Ethyline Glycol sebelum memasuki heat exchanger.

Panas spesifik untuk Ethyline Glycol bervariasi untuk setiap konsentrasi yang berbeda. Berdasarkan Ethylene Glycol Product Guide yang dikeluarkan ME Global maka panas spesifik dapat dicari dengan persamaan $[4 ; 19]$

$$
\mathrm{c}_{\mathrm{p}}=\mathrm{A}+\mathrm{BT}+\mathrm{CT}^{2}
$$

$\mathrm{T}$ disini adalah temperatur dalam satuan ${ }^{0} \mathrm{C}$. A, B dan C adalah konstanta yang ditetapkan untuk masing-masing konsentrasi. Untuk Ethylene Glycol dengan konsentrasi $20 \%$ maka nilai $\mathrm{A}=0,93576 ; \mathrm{B}=3,9963 \times 10-4$ dan $\mathrm{C}=$ $0[4 ; 19]$

\section{Metode Penelitian}

Penelitian dilakukan di Laboratorium Teknik Mesin, Jurusan Teknik Mesin, Politeknik Negeri Pontianak Alat yang digunakan untuk penelitian ini adalah Solar System Trainer merk Hampden H-SST-1A [2].

\subsection{Variabel Penelitian}

Penelitian dilakukan dengan memvariasikan laju aliran fluida yang dipanaskan dalam hal ini adalah air. Sedangkan laju aliran fluida Ethelyn Glycol dibuat tetap. Pengaturan laju aliran masing-masing fluida dilakukan pada valve yang terdapat pada alat ukur laju aliran fluida. Satuan yang digunakan dalam penelitian ini untuk laju aliran baik fluida pemanas maupun fluida yang dipanaskan adalah $\mathrm{ccm}$ atau centimeter cubic per minute.

Adapunvariabel-variabelpenelitianiniadalah:

a. Variabel bebas, adalahvariabel yang menjadi sebab berubahnya variabel terikat. Dalam penelitian ini yang merupakan varibel bebas adalah laju aliran fluida air.

b. Variabel terikat, adalah variabel yang dipengaruhi oleh adanya variabel bebas. Variabel terikat dalam penelitian ini adalah $\mathrm{T}_{5 \text { dan }} \mathrm{T}_{6}$.

c. Variabel Kontrol, adalah variabel yang diatur nilainya agar dapat diketahui pengaruhvariabel bebas terhadap variabel terikat. Variabel control dalam penelitian ini adalah laju aliran fluida pemanas dalam hal ini Ethylin Glycol.

\subsection{Analisis Data}

Analisis data dalam penelitian ini adalah dengan menggunakan teknik analisis kuantitatif deskriptif, yaitu teknik yang digunakan untuk mendeskripsikan atau menyampaikan hasil penelitian dalam bentuk grafik. 


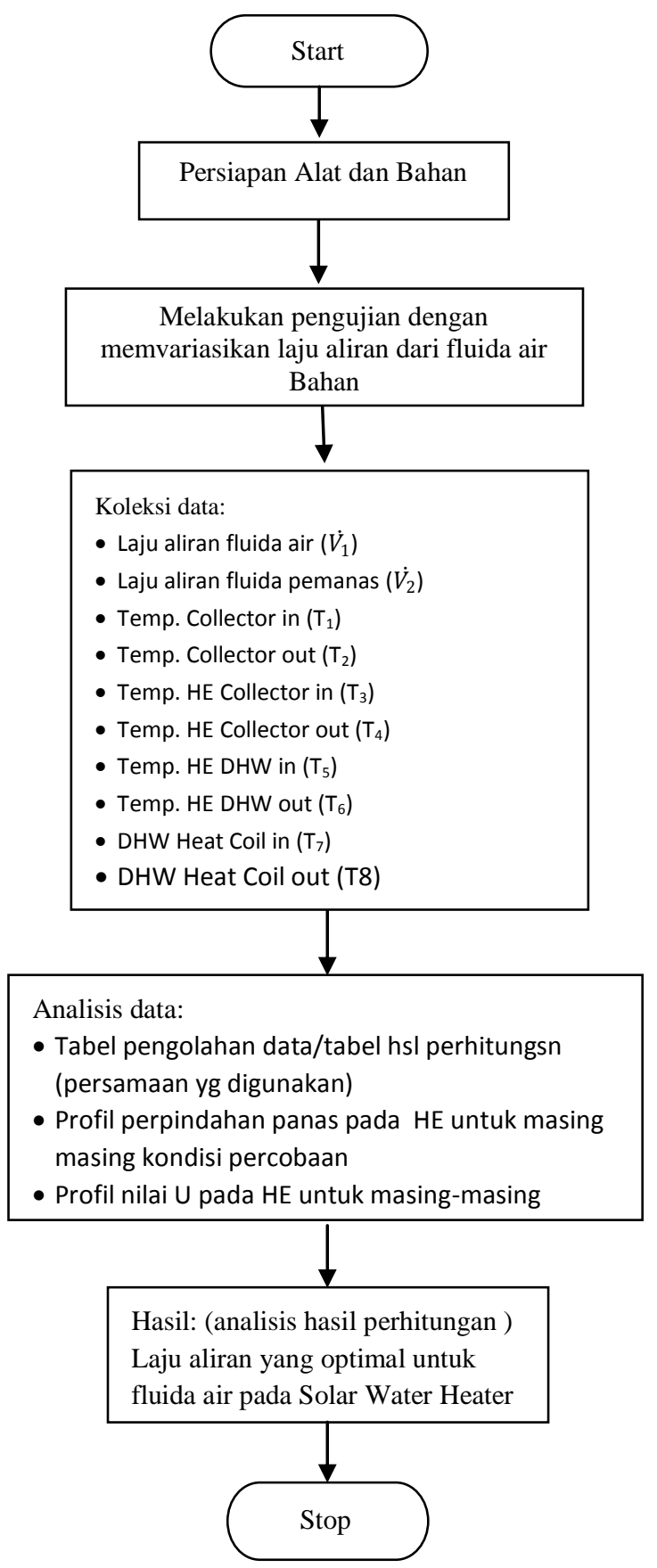

Gambar 5. Diagram alurpenelitian

\section{Pembahasan}

\subsection{Kondisi Penelitian}

Penelitian pengaruh pengaturan laju aliran fluida air terhadap perpindahan panas pada Solar Water Heater ini telah dilakukan di Laboratorium Teknik Mesin Jurusan Teknik Mesin Politeknik Negeri Pontianak.

Penelitian ini dilakukan dengan menggunakan Solar System Trainer merk Hampden H-SST-1A yang telah dilengkapi beberapa alat ukur yaitu laju aliran dan temperatur pada 9 titik. Alat ini mempunyai Solar Panel yang bisa diatur sudutnya, dan dalam penelitiain ini untuk semua eksprimen dilakukan pada sudut kemiringan yang sama yaitu $45^{\circ}$.
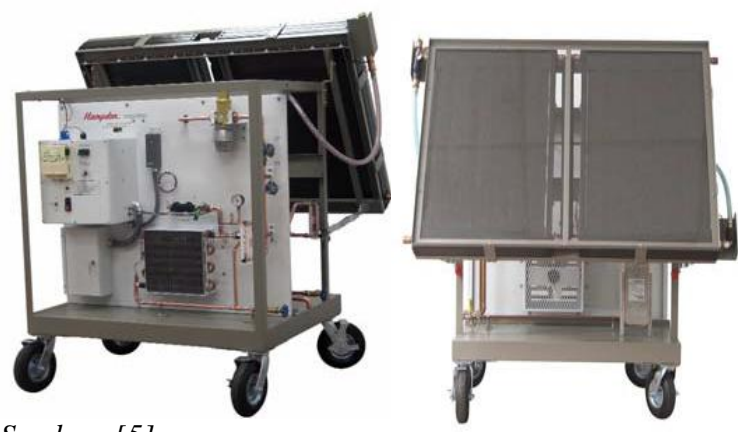

Sumber: [5]

Gambar 6. Solar System Trainer Hampden H-SST-1A

Dalam penelitian ini telah dilakukan pengaturan aliran fluida dimana untuk fluida pemanas yang berupa campuran Ethelyn Glycol atau dipasaran dikenal dengan cairan coolant dibuat tetap untuk semua jenis eksprimen yaitu sebesar $2250 \mathrm{ccm}$. Jalur aliran fluida pemanas pada Solar Water Heater ini dikenal dengan Collector Loop. Sedangkan fluida air yang pada alat ini jalurnya dikenal dengan Domestic Water Heater Loop diatur pada beberapa laju aliran yaitu 1500, 1750, 2000 dan 2450 ccm.

4.2 Grafik Hasil Pengolahan Data Eksprimen

Grafik dibawah ini adalah grafik hasil pengolahan data eksprimen. Adapun grafik tersebut adalah:

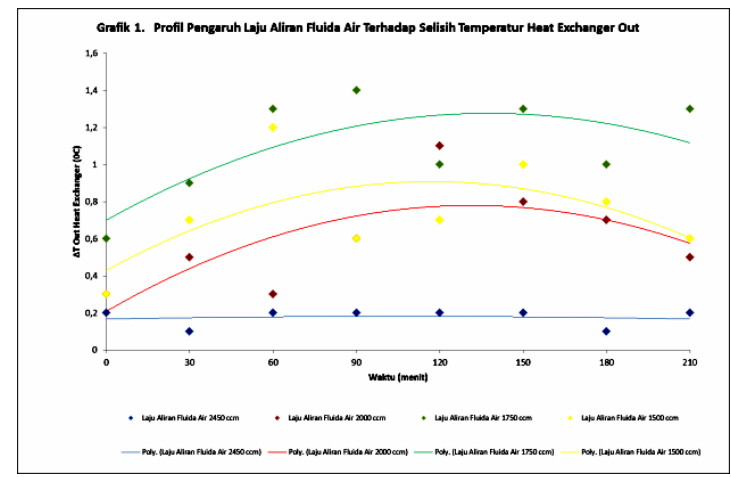

Sumber: Olahan Data (2016)

Gambar 7. GrafikProfilPengaruhLajuAliranFluida Air TerhadapSelisihTemperatur Heat Exchanger Out

Dari 4 kali eksprimen dengan menggunakan laju aliran fluida air pada sisi DHW Loop yang berbeda yaitu $2450 \mathrm{ccm}, 2000 \mathrm{ccm}, 1750 \mathrm{ccm}$ dan $1500 \mathrm{ccm}$ keliatan trend selisih temperatur pada sisi keluar HE dimana jumlah aliran yang lebih besar selisih temperaturnya makin kecil seperti ditunjukan oleh laju aliran fluida air $2450 \mathrm{ccm}$ dan $2000 \mathrm{cmm}$. Tetapi untuk aliran $1750 \mathrm{ccm}$ trendnya malah menunjukan selisih temperatur yang makin tinggi dibandingkan dengan laju aliran $1500 \mathrm{ccm}$.

Untuk perbandingan laju aliran fluida pada sisi DHW Loop kalau dilihat dari selisih temperatur pada sisi keluar HE nampak bahwa laju aliran fluida air sebesar $2450 \mathrm{ccm}$ mempunyai nilai selisih temperatur pada sisi keluar Heat Exchanger yang lebih rendah dibandingkan yang lain. Untuk lebih jelasnya dapat dilihat pada gambar 8. Sehingga dapat dikatakan 
mempunyai nilai efektifitas perpindahan panas yang cukup tinggi.

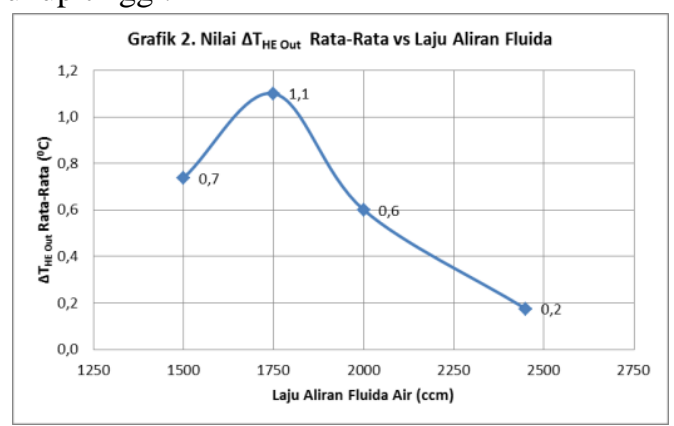

Sumber: Olahan Data (2016)

Gambar 8. Grafik Nilai Selisih Temperatur $\left(\Delta \mathrm{T}_{\mathrm{HE}}\right.$ Out $)$ RataRata vsLajuAliranFluida

Overall Heat Transfer Cooficient (U) merupakan sebuah besaran yang berpengaruh terhadap laju perpindahan panas. Makin besar nilai U, maka makin besar laju perpindahan panas (q) yang terjadi. Dibawah ini adalah gambar yang menunjukkan grafik pengaruh lajualiran fluida terhadap nilai $\mathrm{U}$.

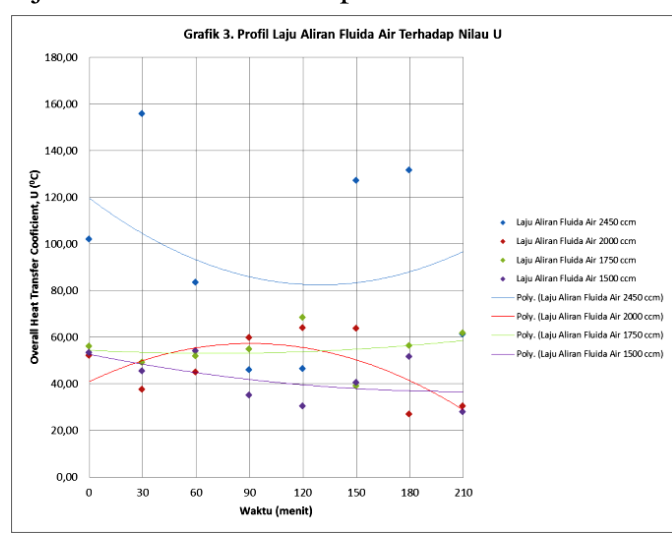

Sumber: Olahan Data (2016)

Gambar 9. Laju Aliran Fluida Air (Collector Loop) Terhadap Overall Heat Transfer Cooficient (U)

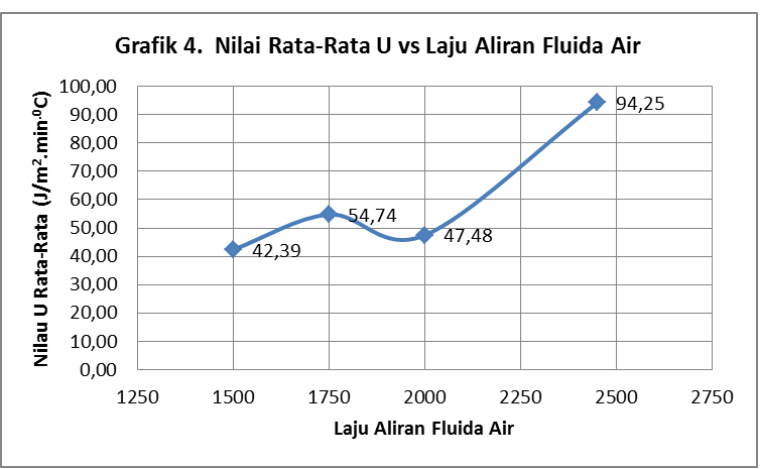

Sumber: Olahan Data (2016)

Gambar 10. Grafik nilai rata-rata U terhadap laju aliran fluida air.

Dari gambar 9 maupun 10 nampak bahwa pada laju aliran fluida air sebesar $2450 \mathrm{ccm}$ mempunyai profil nilai U yang lebih besar dibandingkan dengan profil nilai U yang lain yaitu aliran fluida air 2000, 1750 dan $1500 \mathrm{ccm}$. Makin besar nilai U, maka makin besar jumlah panas yang dibawa oleh fluida air.
Dari hasil eksprimen yang dilakukan dengan 4 laju aliran fluida air yaitu $2450 \mathrm{ccm}, 2000 \mathrm{ccm}, 1750 \mathrm{ccm}$ dan $1500 \mathrm{ccm}$ dilihat dari selisih temperatur pada sisi keluar Heat Exchanger dan profil nilai Overall Cooficient Heat Transfer, U, dapat dikatakan bahwa fluida air yang mengalir pada DHW Loop dengan laju aliran fluida sebesar $2450 \mathrm{ccm}$ mempunyai laju perpindahan panas yang lebih besar dibandingkan dengan yang lain.

\section{Kesimpulan}

Berdasarkan hasil analisa dan pembahasan yang dilakukan pada penelitian ini untuk pengaturan laju aliran fluida air yaitu sisi Domestic Hot Water Loop pada Solar Water Heater maka dapat diambil beberapa kesimpulan sebagai berikut:

- Dari penelitian ini laju aliran fluida air sebesar 2450 ccm sisi DHW Loop untuk Solar Water Heater mempunyai nilai selisih temperatur pada sisi keluar heat exchanger yang lebih kecil dibandingkan dengan besar laju lainnya. Dapat dikatakan makin rendah selisih temperatur pada sisi keluar heat exchanger maka makin efektif pelepasan dan penyerapan panas yang dilakukan oleh fluida dalam heat exchanger.

- Lajualiranfluida air sebesar 2450 ccmsisi DHW Loop untuk Solar Water Heater jugamenunjukannilai Overall Cooficient Heat Transfer (U) yang besardibandingakndenganbesarlajulainnya. Makin besarnyanilai $U$ makamakinbesarjumlahpanas yang dapatdiserapolehfluida air sisi DHW Loop.

\section{Referensi:}

[1].Thirumari murugan, M, Kanna dasan,T, \& Ramasamy, E,"Performance Analysis of Shell and Tube Heat Exchanger Using Miscible System", American Journal of Applied Sciences 5 (5): 548-552, 2008

[2]. Incropera, DeWitt, Bergman, Lavine, "Fundamental Of Heat And Mass Transfer".John\& Willey, Sixth edition, USA

[3]. Cengel, Yunus.A, "Heat Transfer, A Practical Approach”, McGraw Hill Book Co,2nd edition, 2003

[4] ME Global, "Ethylene Glycol Product Guide”, Canada

[5]. Hampden Engineering Co, " Operating Instructions Hampden H-SST-1A Solar System Trainer", East Longmeadow, MA, 2011

\section{Biografi}

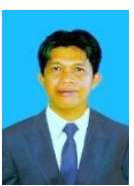

Rusadi, lahir di Sambas tanggal 15 Juli 1972. Lulus dari Strata 1 (S1) Teknik Mesin di Fakultas Teknik Universitas Muhammadiyah Pontianak tahun 1998.dan lulus Strata 2 (S2) Teknik Elektro di Universitas Tanjungpura Pontianak tahun 2017. Dari tahun 1999 sampai saat ini bekerja sebagai staf pengajar di Jurusan Teknik Mesin Politeknik Negeri Pontianak. 